\title{
Strategi Guru dalam Meningkatkan Hasil Belajar Peserta Didik
}

\author{
Anggi Afrina Rambe ${ }^{1}$, Wirdati ${ }^{2}$ \\ anggiafrinarambe@gmail.com ${ }^{1}$, wirdati@fis.unp.ac.id ${ }^{2}$ \\ Universitas Negeri Padang ${ }^{1,2}$
}

\begin{tabular}{|c|c|}
\hline ARTICLE INFO & ABSTRACT \\
\hline Article history: & This study aims to analyze teacher strategies in \\
\hline $\begin{array}{l}\text { Received, } 15 \text { Februari } \\
2022\end{array}$ & $\begin{array}{l}\text { improving student learning outcomes in Islamic religious } \\
\text { education subjects. This research uses a qualitative method }\end{array}$ \\
\hline Revised, 24 Februari 2022 & $\begin{array}{l}\text { with a case study approach, research data is taken through } \\
\text { direct interviews with five informants (school principals, }\end{array}$ \\
\hline $\begin{array}{l}\text { Accepted, } 28 \text { Februari } \\
2022\end{array}$ & $\begin{array}{l}\text { curriculum representatives, three Islamic religious education } \\
\text { teachers) who were selected using a purposive sampling }\end{array}$ \\
\hline Keywords: & nique. To strengthen the interview data, the writer made \\
\hline Strategi Pembelajaran, & $\begin{array}{l}\text { observations by being atrectly involved in the learning } \\
\text { process in the classroom. All interview and observation data }\end{array}$ \\
\hline Hasil Belajar, Pendidikan & were then analyzed thematically using the Miles and \\
\hline Agama Islam & teacher strategies in improving student learning outcomes in \\
\hline Clonflict of Interest: & i) providing material according to the ability of students, ii) \\
\hline None & providing additional learning time, iii) cooperating with \\
\hline Funding: & $\begin{array}{l}\text { homeroom teachers and parents. The three strategies in this } \\
\text { study can be used as reference material for other teachers in }\end{array}$ \\
\hline None & $\begin{array}{l}\text { improving student learning outcomes in Islamic religious } \\
\text { education subjects. }\end{array}$ \\
\hline
\end{tabular}

Corresponding Author: Anggi Afrina Rambe, Department Islamic Education Faculty of Social Science Universitas Negeri Padang, Indonesia, Email: anggiafrinarambe@gmail.com, Phone No: +6282277601076

Copyright@2022, Author(s)

\section{Pendahuluan}

Belajar adalah proses interaksi antara individu dan kelompok untuk melakukan sebuah proses pembelajaran, dalam pembelajaran tersebut adanya seorang guru yang berupaya untuk membantu dalam meningkatkan pengetahuan, sikap dan keterampilan untuk mencapai tujuan secara optimal (Ardhiyah \& Radia, 2020). Pembelajaran adalah hal yang harus diperhatikan untuk memberikan dampak yang lebih nyata pada dunia pendidikan, sebuah interaksi antara guru dan peserta didik juga menjadi tolak ukur terhadap hasil belajar peserta didik (Soffa, 2016; Nurdyansyah \& Fitriyani, 2018; Kurnia, 2019; Sari, 2021). Guru merupakan sentral pendidikan sebab guru sebagai faktor dominan yang mempengaruhi hasil belajar peserta didik (Lestari et al., 2017; Hapnita, 2018; Yarmayani \& Afrila, 2018; Hendriyana, 2018; Eriyanti et al., 2020). Adapun faktor yang dapat mempengaruhi keberhasilan dalam belajar salah satunya adalah guru sebab guru sebagai sentral 
Anggi Afrina Rambe dan Wirdati: Strategi Guru dalam Meningkatkan Hasil Belajar..

dalam proses pembelajaran yang dapat memberikan dampak pada pengetahuan, sikap dan keterampilan pada peserta didik untuk menjadi lebih baik (Supriadi, 2018; Faizah et al., 2019; Kasmar et al., 2019).

Kemajuan teknologi sangat mempengaruhi proses pembelajaran dan hal tersebut memicu tersingkirnya peran guru sebagai sentral dalam pendidikan (Engkizar et al., 2018; Suwardana, 2018; Hidayah, 2019; Anggraini \& Hudaidah, 2021). Dengan adanya kemajuan teknologi tersebut maka penting strategi guru dalam pembelajaran sebab teknologi hanya sebagai pendukung kemajuan pendidikan, namun nilai dari pendidikan adalah mendidik agar anak dapat memilki karakter yang sesuai dengan pendidikan tersebut (Murniyetti et al., 2016; ; Agusti et al., 218; Zafirah et al., 218; Khakim, 2019). Berdasarkan hal tersebut guru hendaknya meningkatkan kreatifitas dalam mengelola kelas agar kehadiran guru bermakna bagi peserta didik.

Strategi merupakan kunci keberhasilan pembelajaran yang memberikan dampak pada proses belajar mengajar (Farhurohman, 2017 dan Chan et al., 2019). Guru dengan sadar merencanakan proses pembelajaran secara sistematis dan guru juga dituntut untuk mempunyai sebuah strategi dalam mengajar (Uang, 2018). Sebagai guru dituntut untuk dapat menyampaikan materi atau pesan secara kreatif dan inovatif dalam menyampaikan materi agar dapat meningkatkan hasil belajar peserta didik.

Undang Undang Nomor 16 Tahun 2010 tentang pengelolaan pendidikan agama pada sekolah menjelaskan Pendidikan agama adalah pendidikan yang memberikan pengetahuan dan membentuk sikap, kepribadian, dan keterampilan peserta didik dalam mengamalkan ajaran agamanya, yang dilaksanakan sekurang-kurangnya melalui mata pelajaran pada semua jalur, jenjang dan jenis pendidikan. Hasbullah et al (2019); Engkizar et al., (2021); Kaputra et al., (2021) mengungkapkan bahwa pendidikan agama Islam menjadi pelajaran yang berupaya dalam mempersiapkan peserta didik sebagai pelajar agar dapat memahami, mengetahui, mengenali, menghayati, mempercayai, bertaqwa berakhlak baik, melaksanakan ajaran agama Islam yang bersumber dari Alquran dan Hadist melalui strategi yang dilakukan guru pada proses pembelajaran di sekolah.

Terkait dengan peningkatan hasil belajar didukung dengan adanya strategi guru yang harus berdampak pada kreatifnya guru dalam menentukan aspek-aspek yang dapat membangkitkan semangat belajar sebab guru yang tidak kreatif dalam proses pembelajaran akan mempengaruhi hasil belajar peserta didik tersebut. Dengan hal tersebut hasil belajar adalah aspek yang perlu diperhatikan sebab berhasil ataupun tidak pembelajaran dilihat dari hasil belajar tersebut dengan adanya strategi yang digunakan oleh guru sebagai upaya untuk mencapai tujuan pembelajaran.

Adapun sekolah yang penulis teliti yaitu sekolah dasar Islam Khaira Ummah yang memiliki keunikan dalam proses pembelajarannya yang selalu mengaitkan dengan nuasa Islam sesuai pada visi sekolah yaitu terwujudnya generasi muda islami terbaik untuk kemaslahatan umat, maka guru pada sekolah tersebut mempunyai upaya yang tinggi untuk meningkatkan hasil belajar peserta didik agar generasi selanjutnya memiliki pegangan iman yang kokoh untuk kemaslahatan umat selanjutnya.

\section{Tinjauan Pustaka}

Pendidikan agama Islam adalah satu mata pelajaran yang bertujuan untuk meningkatkan akhlak mulia dan nilai-nilai spiritual dalam diri anak sebab pendidikan agama Islam juga mengajarkan untuk lebih mengetahui pencipta melalui aktifitas 
sehari-hari dengan amalan yang dapat diaplikasikan dalam keseharian karena materi pada pendidikan agam Islam yang berkesinambungan.

Mata pelajaran pendidikan agama Islam ditawarkan untuk membatu anak-anak yang duduk di bangku sekolah dasar agar memiliki kemampuan menjelaskan tentang Tuhan, memiliki pengalaman untuk memperkuat Iman, taqwa dan berakhlak mulia dengan adanya pembelajaran ini. Sehingga adanya wawasan keislaman yang pada akhirnya bisa melahirkan pandangan dunia islami sehingga membentuk karakter peserta didik (Musya'adah, 2018).

Strategi dapat diartikan sebagai perencanaan dan manajemen untuk mencapai tujuan tertentu dalam proses pembelajaran, namun secara sederhana strategi juga dikatakan sebagai upaya dan pola yang dilakukan seorang guru untuk mencapai tujuan yang telah diterapkan (Talibo, 2018; Arifudin, 2021; Sari et al., 2021; Syafril et al., 2021). Saat guru menerapkan strategi dalam belajar maka dapat mempengaruhi peserta didik untuk belajar lebih giat sebagai peningkatan hasil belajar.

Dalam melaksanakan proses pembelajaran, guru harus mampu menggunakan strategi pembelajaran yang tepat dan harus mampu menciptakan suasana yang kondusif, aktif dan menyenangkan (Sutikna, 2021). Hasbullah et al., (2019) strategi pembelajaran adalah upaya seorang guru dalam mempersiapkan peserta didik dalam pembelajaran, pertama; pembelajaran adalah sebuah upaya seorang guru untuk mengorganisasikan lingkungan agar tercipta kondisi belajar yang baik, kedua; pembelajaran merupakan proses membantu peserta didik dalam berkehidupan di masyarakat. Jadi strategi yang telah dijelaskan tersebut adalah strategi yang mengarah pada proses belajar mengajar yang menyangkut antara guru dan peserta didik. Kemudian strategi juga diartikan sebagai pola yang direncanakan dan ditetapkan secara sengaja untuk melakukan kegiatan atau tindakan untuk mencapai tujuan yang tekah ditetapkan (Merta, 2020).

Berdasarkan pada direktorat tenaga kependidikan (2008) Ada beberapa strategi pembelajaran diantaranya; pertama, strategi pengorganisasian; kedua, strategi penyampaian pembelajaran; ketiga, strategi pengelolaan pembelajaran. Kemudian strategi yang digunakan guru tergantung pada pendekatan yang dilakukan guru kepada peserta didik.

Kemudian Iskandarwassid \& Sunendar (2008) juga mengklasifikasikan jenis strategi antara lain: (1) Berdasarkan penekanan komponen dalam program pengajaran yaitu: strategi yang berpusat pada pengajar, strategi yang berpusat pada peserta didik dan strategi yang berpusat pada materi pengajaran); (2) Berdasarkan kegiatan pengelolaan pesan atau materi yaitu strategi pembelajaran ekspositori dan strategi pembelajaran heuristik; (3) Berdasarkan Proses pengelolaan pesan atau materi yaitu strategi pembelajaran dedukasi dan strategi pembelajaran Induksi; (4) Berdasarkan cara memproses penemuan yaitu strategi pembelajaran ekspositoris dan strategi pembelajaran discovery.

Strategi juga memiliki faktor yang medukung penerapan strategi pembelajaran yaitu, 1) tujuan yang hendak dicapai, 2) materi pelajaran, 3) peserta didik, 4) situasi, 5) fasilitas, 6) guru. Dalam hal ini strategi berpengaruh pada setiap faktor yang akan dijalankan dalam pembelajaran dan hasil belajar juga sangat berpengaruh pada guru sebab guru harus memiliki strategi untuk hasil belajar sebagai tujuan dari pembelajaran.

Hasil belajar adalah kemampuan yang dimiliki peserta didik setelah menerima pengalaman dari proses pembelajaran yang dapat memperbaiki dan menambah 
Anggi Afrina Rambe dan Wirdati: Strategi Guru dalam Meningkatkan Hasil Belajar..

kognitif, afektif dan psikomotor peserta didik (Purwono, 2014). Hasil belajar tidak hanya mengenai nilai akademik yang selalu menjadi pegangan oleh setiap orang namun hasil belajar juga dapat memberikan dampak pada perilaku peserta didik dan keterampilan yang dimiliki oleh peserta didik.

Kemudian hasil belajar merupakan kemampuan yang dimiliki peserta didik setelah menerima pengalaman dari proses pembelajaran yang dapat memperbaiki dan menambah kognitif, afektif dan psikomotor peserta didik (Purwono, 2014). Firmansyah (2015) menjelaskan hasil belajar adalah kemampuan yang telah dimiliki oleh peserta didik setelah mengalami proses belajar yang akhirnya memperoleh sebuah perubahan pada diri peserta didik. Hasil belajar juga diartikan sebagai sebuah tindakan evaluasi yang dapat mengungkapkan sebuah aspek proses berpikir (cognitive), aspek kejiwaan atau nilai dan sikap (affective) dan aspek keterampilan (psychomotor) yang melekat pada diri setiap peserta didik yang dapat memberikan sebuah perubahan pada peserta didik. Adapun faktor-faktor yang mempengaruhi hasil belajar terbagi menjadi dua yaitu internal dan eksternal. Kemudian hasil belajar juga memilki tiga indikator yaitu kognitif, afektif dan psikomotor.

\section{Metode}

Adapun jenis penelitian yang digunakan pada hal ini yaitu penelitian kualitatif dengan pendekatan studi kasus pendekatan studi kasus pada penelitian kualitatif digunakan pada saat peneliti ingin menemukan pengetahuan yang mendalam dan mengeksplorasi data terhadap suatu fenomena yang belum pernah diungkap sebelumnya dan mengungkap fenomena untuk mendapatkan data yang luas maupun dalam unit terkecil. Sumber data diambil melalui lima orang informan yaitu guru yang mengajar pendidikan agama Islam dan dokumentasi.

Kemudian istrumen yang digunakan yaitu satu set protokol wawancara yang sudah di validisi kepada satu pakar sesuai pada bidang penelitian ini. Terkait dengan teknik pengambilan data melalui observasi, wawancara dan dokumentasi serta dianalisis dengan teknik analisis yang disesuaikan pada Miles dan Huberman (2008).

\section{Hasil dan Pembahasan}

Berdasarkan hasil wawancara terkait strategi guru dalam meningkatkan hasil belajar peserta didik, penulis menemukan tiga strategi guru dalam meningkatkan hasil belajar peserta didik di sekolah dasar Islam Khaira Ummah. Adapun strategi guru dalam meningkatkan hasil belajar peserta didik adalah memberikan materi sesuai kemampuan, memberikan waktu tambahan dan menjalin kerjasama antara guru, wali kelas dan guru pendidikan agama Islam. Agar lebih mudah dipahami penulis akan mendeskripsikan hasil tersebut melalui gambar berikut:

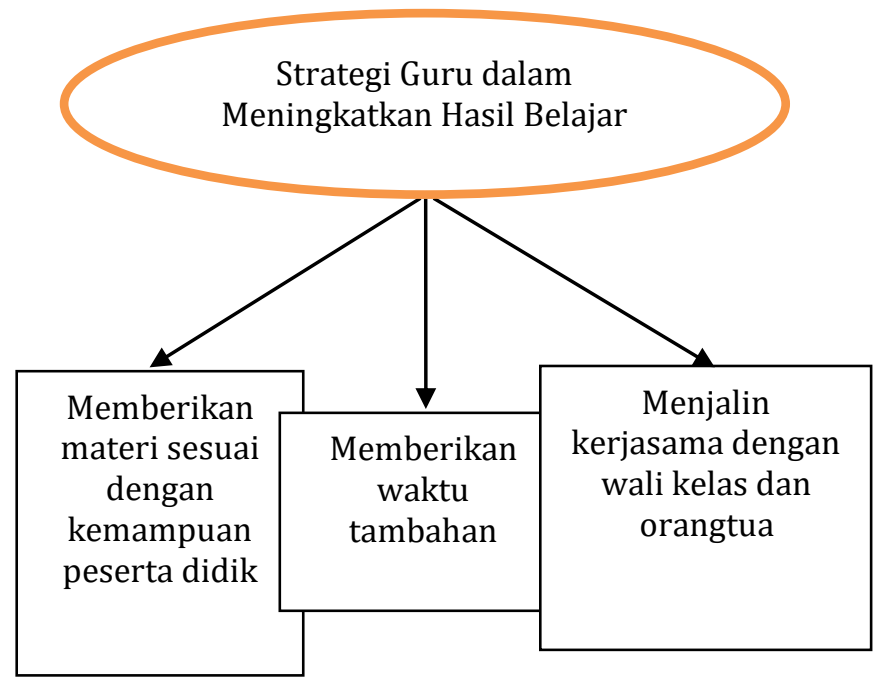




\section{Gambar 1. Strategi Guru Dalam Meningkatkan Hasil Belajar}

Terkait dengan ketiga temuan diatas penulis akan mendeskripsikan maksud tersebut sebagai berikut:

Pertama, memberikan materi sesuai dengan kemampuan peserta didik, ketika ada beberapa peserta didik yang memiliki kemampuan lebih maka peserta didik tersebut diberikan pengayaan untuk memperdalam pengetahuannya dan ketika peserta didik yang memiliki kemampuan rendah maka peserta didik tersebut diberikan remedial untuk mengejar ketertinggalannya tersebut.

Kedua, memberikan waktu tambahan yaitu seperti memberikan waktu luang misalnya ketika jam pelajaran sudah selesai atau ketika waktu pulang sekolah peserta didik yang kemampuan akademiknya rendah disuruh untuk tinggal di kelas agar guru dapat memberikan pengajaran lebih kepada peserta didik tersebut.

Ketiga, menjalin kerjasama dengan wali kelas dan orangtua yaitu membuat grup Whats App antara guru dengan orangtua agar orangtua juga mengetahui perkembangan anak dan dapat memberikan perhatian lebih ketika di rumah. Kemudian jika anak yang butuh perhatian lebih maka orangtua akan dipanggil untuk mendiskusikan perkembangan anak.

Ketiga strategi tersebut diungkapkan oleh informan 1 sebagaimana yang terdapat dalam kutipan wawancara berikut:

... untuk itu kita harus mendekati anak dan memberikan waktu tambahan untuk dapat bertanya apa masalah yang membuat anak tersebut tidak bersemangat dalam belajar,... setelah itu kita akan berdiskusi bersama wali kelas untuk mencari solusi agar anak tertarik dalam belajar yang akan dibantu oleh orangtua.

Informan 2 menjelaskan sebagaimana yang terdapat dalam kutipan wawancara berikut:

...dalam upaya agar anak rajin belajar maka harus menjalin kerjasama dengan wali kelas dan orangtua untuk membangkitkan semangat belajar anak..., ketika materi pembelajaran sesuai dengan kemampuan anak maka anak akan tertarik dalam belajar karena sesuai dengan kemampuan anak.

Informan 3 juga menjelaskan sebagaimana yang terdapat dalam kutipan wawancara berikut:

...berkomunikasi baik dengan wali kelas dan orangtua mengenai perkembangan anak, ...kemudian anak diberikan waktu lebih dengan cara menyuruh anak tetap tinggal di kelas bersama kita kemudian memotivasi anak untuk tetap semangat dalam belajar.

Untuk memperkuat hasil temuan wawancara, penulis juga melakukan observasi langsung pada saat guru mengajar di kelas untuk melihat suasana kelas pada saat pembelajaran berlangsung sebagaimana yang terlihat pada gambar berikut: 
Anggi Afrina Rambe dan Wirdati: Strategi Guru dalam Meningkatkan Hasil Belajar..
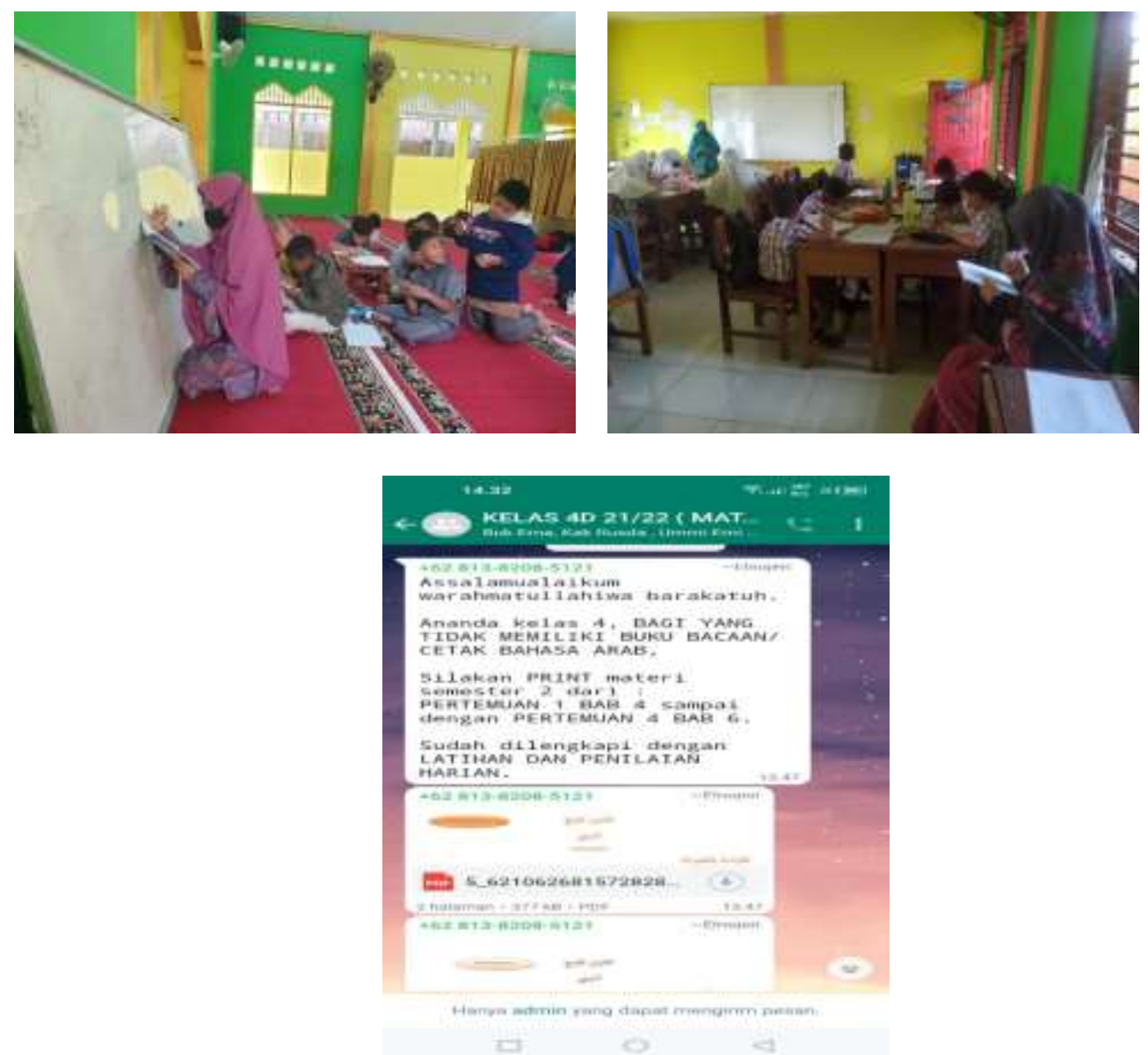

Gambar 2. Observasi Kegiatan Pembelajaran

Strategi yang digunakan pada sekolah dasar Islam Khaira Ummah dilakukan dengan menggunakan beberapa tahapan yang diharapkan dapat meningkatkan hasil belajar, dengan adanya tiga strategi tersebut memberikan dampak positif dalam proses pembelajaran. Oleh karena itu, tiga strategi tersebut akan penulis deskripsikan untuk memahami maksud pada temuan ini yaitu:

Pertama, memberikan materi sesuai dengan kemampuan peserta didik, ketika ada beberapa peserta didik yang memiliki kemampuan lebih maka peserta didik tersebut diberikan pengayaan untuk memperdalam pengetahuannya dan ketika peserta didik yang memiliki kemampuan rendah maka peserta didik tersebut diberikan remedial untuk mengejar ketertinggalannya tersebut. Dalam hadist Nabi SAW juga menerangakan bahwa kita harus berbicara sesuai pada kemampuannya, Ali bin Abi Thalib radhiyallahu 'anhu berkata:

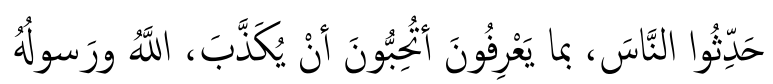

Artinya: "Bicaralah kepada orang lain sesuai dengan apa yang mereka pahami. Apakah Engkau ingin Allah dan Rasul-Nya didustakan?” (HR. Bukhari no. 127).

Kemudian Syaikh 'Abdul Muhsin Al-Abbad hafizhahullah juga berkata: 


$$
\text { فكون الإنسان يُحَّثث بشيء لا يعقله ولا يطيقه فهمه قد يترتب عليه مضرة }
$$

Artinya: "Ketika seseorang berbicara kepada orang lain tentang hal yang tidak digapai oleh akalnya, dan tidak mampu ia cerna, terkadang akan menimbulkan bahaya baginya" (Syarah Sunan Abi Daud, 3: 12).

Oleh karena itu, guru harus bisa menyampaikan materi sesuai pada kemampuan berpikirnya agar perta didik dapat memahami yang disampaikan oleh guru tersebut. Jika peserta didik yang lemah dalam memahami materi yang disampaikan oleh guru maka peserta didik tersebut diberikan sesuai dengan kemampuannya.

Kedua, memberikan waktu tambahan yaitu seperti memberikan waktu luang misalnya ketika jam pelajaran sudah selesai atau ketika waktu pulang sekolah peserta didik yang kemampuan akademiknya rendah disuruh untuk tinggal di kelas agar guru dapat memberikan pengajaran lebih kepada peserta didik tersebut.

Terkait dengan memberikan waktu tambahan kepada peserta didik guru berupaya untuk mengulang pembelajaran agar peserta didik dapat memahami pembelajaran yang telah diajarkan, sebab sesuatu yang dilakukan berulang-ulang akan memberikan pemahaman yang lebih banyak untuk dipelajari. Pengulangan pembelajaran sesuai pada metode murajaah Alquran. Muraja'ah adalah pengulangan, muraja'ah secara kontinyu akan menguatkan hafalan, muraja'ah secara kontinyu lebih penting dari hafalan itu sendiri, muraja'ah secara kontinyu itulah hakekat dari menghafal. Jadi pemberian waktu tambahan oleh guru dapat memberikan dampak pada peserta didik lebih ingat dengan pembelajaran yang sering dipelajari.

Ketiga, Menjalin kerjasama dengan wali kelas dan orangtua yaitu membuat grup Whats App antara guru dengan orangtua agar orangtua juga mengetahui perkembangan anak dan dapat memberikan perhatian lebih ketika dirumah. Kemudian jika anak yang butuh perhatian lebih maka orangtua akan dipanggil untuk mendiskusikan perkembangan anak. Dengan adanya kerja sama tersebut sesuai dengan faktor-faktor yang dapat mempengaruhi hasil belajar terbagi menjadi dua yaitu; faktor internal yaitu aspek psikologis (intelegensi, perhatian, minat dan motivasi dan kesiapan) dan faktor eksternal yaitu aspek keluarga, sekolah dan aspek masyarakat (Hapnita et al., 2018). Jadi kerjasama natara orangtua, wali kelas dan guru pendidikan agama Islam termasuk pada faktor eksternal yaitu keluarga yang mendukung dalam meningkatkan hasil belajar peserta didik.

Berdasarkan hal di atas bahwa peningkatan hasil belajar bisa dilakukan melalui strategi guru untuk memberikan pengaruh terhadap peningkatan tersebut sebab guru memilki pola yang harus dilaksanakan dengan kreatifitas guru yang memungkinkan untuk memberikan semangat belajar pada peserta didik untuk mencapai tujuan dari pembelajaran.

\section{Simpulan}

Adapun strategi yang dilakukan guru dalam meningkatkan hasil belajar peserta didik terdapat tiga strategi guru yaitu memberikan materi sesuai dengan kemampuan peserta didik, memberikan waktu tambahan dan menjalin kerjasama antara guru, wali kelas dan guru pendidikan agama Islam. Dengan ketiga strategi tersebut diharapkan dapat meningkatkan hasil belajar peserta didik yang menunjang pada prestasi belajar. Srategi guru juga harus diperhatikan dalam proses pembelajaran 
Anggi Afrina Rambe dan Wirdati: Strategi Guru dalam Meningkatkan Hasil Belajar..

karena dampak dari proses pembelajaran tidak hanya sebatas ilmu pengetahuan yang disimpan di dalam kepala peserta didik namun perlu adanya peningkatan nilai sikap dan keterampilan yang jarang diperhatikan dalam bangku pendidikan karena terlalu fokus dalam peningkatan pengetahuan atau kognitif peserta didik.

\section{Referensi}

Agusti, F. A., Zafirah, A., Engkizar, E., Anwar, F., Arifin, Z., \& Syafril, S. (2018). The Implantation of Character Values toward Students through Congkak Game for Mathematics Instructional Media. Jurnal Penelitian Pendidikan, 35(2), 132142.

Al-Bukhari, al-Imam al-Hafidz Abi 'Abdillah Ibn Isma'il, Shahīhu-l-Bukhāri, Dār Ibn Hazm, Beirut-Libanon, 2003

Anggraini, W., \& Hudaidah, H. (2021). Reformasi Pendidikan Menghadapi Tantangan Abad 21. Journal on Education, 3(3), 208-215.

Ardhiyah, M. A., \& Radia, E. H. (2020). Pengembangan Media Berbasis Adobe Flash Materi Pecahan Matematika untuk Meningkatkan Hasil Belajar. Jurnal Penelitian Dan Pengembangan Pendidikan, 4(3), 479-485.

Arifudin, O. (2021). Manajemen Strategik Teori Dan Implementasi.

As-Sajistani, Abu Dawud Sulaiman Bin Al-Asy, Sunan Abi Dawud, Cet.2, Riyadh: Maktabah Al-Ma'arif, 2007

Chan, F., Kurniawan, A. R., Herawati, N., Efendi, R. N., \& Mulyani, J. S. (2019). Strategi guru dalam mengelola kelas di sekolah dasar. International Journal of Elementary Education, 3(4), 439-446.

Engkizar, E., Muliati, I., Rahman, R., \& Alfurqan, A. (2018). The Importance of Integrating ICT into Islamic Study Teaching and Learning Process. Khalifa: Journal of Islamic Education, 1(2), 148-168.

Engkizar, E., Munawir, K., Kaputra, S., Arifin, Z., Syafril, S., Anwar, F., \& Mutathahirin, M. (2021). Building of Family-based Islamic Character for Children in Tablighi Jamaat Community. Ta'dib, 24(2), 116-126.

Eriyanti, F., Alhadi, Z., Moeis, I., Yulastri, A., \& Syafril, S. (2020, April). The Impact of Government Policies towards the Economy and Education of Fishermen's Children in Padang City. In IOP Conference Series: Earth and Environmental Science (Vol. 469, No. 1, p. 012057). IOP Publishing.

Faizah, Z., Hanief, M., \& Dina, L. N. A. B. (2019). Profesionalisme Guru Dalam Meningkatkan Mutu Pendidikan di Madarsah Ibtidaiyah Tahfidz Al-Asyhar Malang. JPMI: Jurnal Pendidikan Madrasah Ibtidaiyah, 1(3), 134-140.

Farhurohman, 0. (2017). Faktor Kunci Keberhasilan Komponen Penyusunan Manajemen Perencanaan Stategis Sekolah. Tarbawi: Jurnal Keilmuan Manajemen Pendidikan, 3(01), 77-89.

Fimansyah, D. (2015). Pengaruh Strategi pembelajaran dan minat belajar terhadap hasil belajar matematika. Judika (Jurnal Pendidikan UNSIKA), 3(1).

Hapnita, W. (2018). Faktor internal dan eksternal yang dominan mempengaruhi hasil belajar menggambar dengan perangkat lunak siswa kelas XI teknik gambar bangunan SMK N 1 Padang tahun 2016/2017. CIVED (Journal of Civil Engineering and Vocational Education), 5(1). 
Hasbullah, H., Juhji, J., \& Maksum, A. (2019). Strategi belajar mengajar dalam upaya peningkatan hasil belajar pendidikan agama islam. EDURELIGIA: Jurnal Pendidikan Agama Islam, 3(1), 17-24.

Hendriana, E. C. (2018). Pengaruh keterampilan guru dalam mengelola kelas terhadap hasil belajar peserta didik di sekolah dasar. JPDI (Jurnal Pendidikan Dasar Indonesia), 3(2), 46-49.

Hidayah, A. S. (2019). Eksistensi Adab Belajar Menghadapi Era Dirupsi Pendidikan Dalam Peradaban Otomasi. Jurnal Tawadhu, 3(2), 823-836.

Kaputra, S., Engkizar, E., Akyuni, Q., Rahawarin, Y., \& Safarudin, R. (2021). Dampak Pendidikan Orang Tua Terhadap Kebiasaan Religius Anak dalam Keluarga Jama'ah Tabligh. Al-Tadzkiyyah: Jurnal Pendidikan Islam, 12(2), 249-268.

Kasmar, I. F., Amnda, V., Mutathahirin, M., Maulida, A., Sari, W. W., Putra, S., ... \& Engkizar, E. (2019). The Concepts of Mudarris, Mu'allim, Murabbi, Mursyid, Muaddib in Islamic Education. Khalifa: Journal of Islamic Education, 3(2), 107125.

Kemenag RI. 2010. Permenag RI No. 16 tahun 2010 ttg Pengelolaan Pendidikan Agama pada Sekolah. Jakarta: Kemenag RI.

Khakim, M. M. (2019). Strategi Kepala Madrasah Dalam Meningkatkan Mutu Pendidikan di Madrasah Tsanawiyah Negeri 2 Brebes (Doctoral dissertation, IAIN Purwokerto).

Kurnia, R. (2019). Strategi Guru Dalam Meningkatkan Hasil Belajar Belajar Pembelajaran Akidah Akhlak Dimadrsah Ibtidaiyah Hidayatul Mubtadiin Tasikmadu Malang. JPMI: Jurnal Pendidikan Madrasah Ibtidaiyah, 1(1), 48-55.

Lestari, I. A., Amir, H., \& Rohiat, S. (2017). Hubungan persepsi siswa kelas X MIPA di SMA Negeri sekota Bengkulu tahun ajaran 2016/2017 tentang variasi gaya mengajar guru dengan hasil belajar kimia. Alotrop, 1(2).

Merta Sari, N. O. V. I. (2020). Implementasi Strategi Pembelajaran Guided Note Taking (Catatan Terbimbing) Terhadap Minat Belajar Siswa Kelas Iii Pada Mata Pelajaran Akidah Akhlak Di Madrasah Ibtidayah Al-Awwal Palembang (Doctoral dissertation, UIN Raden Fatah Palembang).

Murniyetti, M., Engkizar, E., \& Anwar, F. (2016). Pola pelaksanaan pendidikan karakter terhadap siswa sekolah dasar. Jurnal Pendidikan Karakter, 6(2).

Musya'adah, U. (2018). Arti Seorang Pendidik Untuk "Kids Zaman Now". MODELING: Jurnal Program Studi PGMI, 5(2), 157-170.

Nurdyansyah, N., \& Fitriyani, T. (2018). Pengaruh Strategi Pembelajaran Aktif Terhadap Hasil Belajar Pada Madrasah Ibtidaiyah. Universitas Muhammadiyah Sidoarjo.

Purwono, J. (2014). Penggunaan Media Audio-Visual pada Mata Pelajaran Ilmu Pengetahuan Alam di Sekolah Menengah Pertama Negeri 1 Pacitan. Jurnal teknologi pendidikan dan pembelajaran, 2(2).

Putri, D. P. (2018). Pendidikan karakter pada anak sekolah dasar di era digital. $A R$ RIAYAH: Jurnal Pendidikan Dasar, 2(1), 37-50.

Sari, I. P. (2021). Pengaruh Model Pembelajaran Problem Based Learning Terhadap Hasil Belajar Siswa Pada Mata Pelajaran Bahasa Indonesia Di Kelas V Sd Negeri 24 Kota Bengkulu (Doctoral dissertation, UIN Fatmawati Sukarno). 
Anggi Afrina Rambe dan Wirdati: Strategi Guru dalam Meningkatkan Hasil Belajar..

Sari, W., Anwar, F., Wirdati, W., \& Engkizar, E. (2021). Metode Diskusi Guru Pendidikan Agama Islam dalam Meningkatkan Kepercayaan Diri Peserta Didik. Jurnal Pendidikan Tambusai, 5(3), 8904-8909.

Shoffa, S. (2016). Penerapan Strategi Meaningful Learning dalam Meningkatkan Hasil Belajar Mahasiswa Pendidikan Matematika UM Surabaya pada Mata Kuliah Pengantar Pendidikan. MUST: Journal of Mathematics Education, Science and Technology, 1(2), 137-143.

Supriadi, D. (2018). Implementasi Manajemen Inovasi dan Kreatifitas Guru dalam Meningkatkan Mutu Pembelajaran. Indonesian Journal of Education Management \& Administration Review, 1(2), 125-132.

Sutikno, M. S. (2021). Strategi Pembelajaran. Penerbit Adab.

Suwardana, H. (2018). Revolusi Industri 4. 0 Berbasis Revolusi Mental. JATI UNIK: Jurnal Ilmiah Teknik Dan Manajemen Industri, 1(2), 109-118.

Syafril, S., Yaumas, N. E., Engkizar, E., Jaafar, A., \& Arifin, Z. (2021). Sustainable Development: Learning the Quran Using the Tartil Method. Al-Ta lim Journal, 28(1), 1-8.

Talibo, I. (2018). Fungsi Manajemen dalam Perencanaan Pembelajaran. Jurnal Ilmiah Iqra', 7(1).

Uang, Y. (2018). Menakar Eksistensi Guru: Antara Konsep dan Realita dalam Standar Proses Pembelajaran. Jurnal Pendidikan Islam Indonesia, 2(2), 237245.

Yarmayani, A., \& Afrila, D. (2018). Analisis faktor lingkungan belajar yang mempengaruhi hasil belajar siswa. Jurnal Ilmiah Dikdaya, 8(1), 135-149.

Zafirah, A., Agusti, F. A., Engkizar, E., Anwar, F., Alvi, A. F., \& Ernawati, E. (2018). Penanaman nilai-nilai karakter terhadap peserta didik Melalui permainan congkak sebagai media pembelajaran. Jurnal Pendidikan Karakter, 8(1). 